\title{
Prevalence of attention-deficit/hyperactivity disorder symptoms and their associations with sleep schedules and sleep-related problems among preschoolers in mainland China
}

Hui Cao ${ }^{1 \dagger}$, Shuangqin Yan ${ }^{1 \dagger}$, Chunli Gu${ }^{1}$, Sumei Wang ${ }^{1}$, Lingling $\mathrm{Ni}^{2,3}$, Huihui Tao ${ }^{2,3}$, Ting Shao ${ }^{2,3}$, Yeqing Xu ${ }^{1}$ and Fangbiao Tao ${ }^{2,3^{*}}$

\begin{abstract}
Background: Attention-deficit/hyperactivity disorder (ADHD) among children is an increasing public health concern. The identification of behavioral risk factors, including sleep quality, has important public health implications for prioritizing behavioral intervention strategies for ADHD. Herein, this study aimed to investigate the prevalence of high levels of ADHD symptoms and to explore the association between sleep schedules, sleep-related problems and ADHD symptoms among preschoolers aged 3 to 6 years in mainland China.

Methods: A cross-sectional study was conducted, comprising a large sample of 15,291 preschoolers in Ma'anshan city of Anhui Province in China. ADHD symptoms were assessed by the 10-item Chinese version of the Conners Abbreviated Symptom Questionnaire (C-ASQ). Sleep-related variables included caregivers' responses to specific questions addressing children's daytime and nighttime sleep schedules, as well as sleep-related behaviors. Data on other factors were also collected, such as socio-demographic characteristics, TV viewing duration on weekdays and weekends, and outdoor activities. Logistic regression models were used to analyze the relationships between sleep schedules, sleep-related problems and ADHD symptoms.

Results: Approximately $8.6 \%$ of the total sample of preschoolers had high levels of ADHD symptoms, with boys having higher levels than girls (9.9\% vs. 7.2\%). In the logistic regression analysis, after adjusting for TV viewing duration, outdoor activities, and socio-demographic characteristics, delayed bedtime was significantly associated with a risk of high levels of ADHD symptoms, with odds ratios (OR) of 2.50 [95\% confidence interval (CI): $2.09 \sim 3$. $00]$ and 2.04 (95\% Cl: $1.72 \sim 2.42$ ) for weekdays and weekends, respectively. Longer time falling asleep ( $\geq 31 \mathrm{~min}$ ) $(O R=1.76,95 \% \mathrm{Cl}: 1.47 \sim 2.11)$, no naps $(O R=1.57,95 \% \mathrm{Cl}: 1.34 \sim 1.84)$ and frequent sleep-related problems $(O R=4.57,95 \% \mathrm{Cl}: 3.86 \sim 5.41)$ were also significantly associated with an increased risk of high levels of ADHD symptoms, while longer sleep duration (> $8.5 \mathrm{~h}$ ) was associated with a decreased risk of high levels of ADHD symptoms $(O R=0.76,95 \% \mathrm{Cl}: 0.67 \sim 0.87)$.

(Continued on next page)
\end{abstract}

\footnotetext{
*Correspondence: taofangbiao1@126.com

${ }^{\dagger}$ Equal contributors

${ }^{2}$ Department of Maternal, Child and Adolescent Health, School of Public

Health, Anhui Medical University, 81 Mei Shan Road, Hefei, Anhui 230032,

China

${ }^{3}$ Anhui Provincial Key Laboratory of Population Health and Aristogenics,

Hefei 230032, China

Full list of author information is available at the end of the article
} 
(Continued from previous page)

Conclusions: ADHD symptoms are prevalent in preschoolers in Ma'anshan region, China. Undesirable sleep schedules and sleep-related problems among preschoolers confer a risk of ADHD symptoms, highlighting the finding that beneficial and regular sleep habits potentially attenuate ADHD symptoms among preschoolers.

Keywords: Sleep, Sleep-related problems, Inattention, Hyperactivity/impulsivity, Preschooler

\section{Background}

Attention-deficit/hyperactivity disorder (ADHD) among children is a rising public health concern and a common psychiatric disorder with a childhood onset, defined by age-inappropriate symptoms of inattention and/or hyperactivity and impassivity [1]. It is well known that ADHD is associated with psychiatric and developmental disorders. The potential mechanism of ADHD is still under study. It has been associated with a broad range of negative outcomes for affected subjects [2] and with a considerable financial burden [3]. The worldwide pooled prevalence of ADHD has been estimated to be $5.29 \%$ ( $95 \%$ CI: $5.01 \sim 5.56$ ), as noted in an extensive literature review of relevant articles from North America, South America, Europe, Africa, Asia, Oceania, and the Middle East [4]. Few populationbased epidemiological studies on ADHD symptoms have been conducted in China. One such study found that the weighted 3-month prevalence rates across 3 consecutive years of ADHD symptoms (from the seventh grade to the ninth grade) were 7.5, 6.1 and 3.3\% [5]. Although ADHD is most typically diagnosed during the school years, there is an increasing tendency for identification to occur among preschoolers [6]. Several longitudinal studies suggest that ADHD symptoms in preschoolers might persist through elementary school $[6,7]$ and into adulthood $[8,9]$. Therefore, we surmised that a thorough understanding of the epidemiological features of ADHD symptoms in preschool children is important for preventing and managing this disorder.

Sleep has been referred to as a "window to the central nervous system", owing to its close associations with many other neurophysiological variables. Children are highly vulnerable to sleep disruptions in early childhood, perhaps due to the complexity of the sleep process and children's reliance on caregivers for achieving and maintaining sleep. Childhood sleep problems have been linked to a range of adverse health outcomes. Recently, Sivertsen, et al. showed that a short sleep duration ( $\leq$ $10 \mathrm{~h}$ ) and frequent nocturnal awakenings ( $\geq 3$ times) at 18 months of age significantly predicted both the concurrent and later incidence of emotional and behavioral problems at 5 years of age [10]. Nelson, et al. reported that sleep problems were negatively associated with performance on tasks assessing working memory and interference suppression inhibition, even after controlling for general cognitive abilities [11]. The relation between sleep and ADHD has gained renewed interest since clinicians and researchers observed that sleep-related problems and complaints are relatively common among children with ADHD. Shorter sleep duration and sleep disturbances have been found to appear early and predate the clinical diagnosis of ADHD [12]. In addition, the ADHD group had significantly higher subscales and total scores assessed by the Children's Sleep Habits Questionnaire (CSHQ) [13]. In addition, a meta-analysis comparing sleep in children with ADHD versus sleep in controls indicated that children with ADHD had significantly higher bedtime resistance, more sleep onset difficulties, night awakenings, difficulties with morning awakenings, sleep-disordered breathing, and daytime sleepiness in subjective studies [14].

While there is a wealth of studies on sleep patterns in children with ADHD, few studies have focused on nonclinical samples of preschoolers or investigated the direct association between sleep-related phenomena and ADHD symptoms. In addition, most existing studies have been limited to Western populations. Therefore, we aimed to conduct a study to investigate the prevalence of high levels of ADHD symptoms in a nonclinical sample of Chinese preschoolers and to explore the relationships between sleep schedules, sleeprelated problems and ADHD symptoms.

\section{Methods \\ Participants}

In 2014, a school-based cross-sectional survey was conducted in 91 kindergartens in Ma'anshan city of Anhui Province in China. A total of 16,439 children were recruited to participant in the study. Cases with missing values for more than $15 \%$ of items were excluded from this study. Ultimately, the data of the 15,291 preschoolers ( 8218 boys and 7073 girls) with complete assessments by their caregivers were used for data analysis. The participants' ages ranged from 3 to 6 years old, with a mean age of 4.91 years (standard deviation $(\mathrm{SD})=1.00$ ).

\section{Instruments}

A self-administered questionnaire containing information on socio-demographic characteristics, TV viewing duration on weekdays and weekends, outdoor activities, 
sleep schedules and sleep-related problems, and ADHD symptoms was completed by preschoolers' caregivers at home and returned to the teacher the next day. Then, graduate students majoring in Maternal and Child Health recovered all questionnaires from the kindergartens one by one. To guarantee the quality of questionnaires, quality control was conducted by teachers and graduate students separately.

\section{Sleep schedules and sleep-related problems}

The sleep questionnaire adapted from the Children's Sleep Habits Questionnaire (CSHQ) [15], Pittsburgh Sleep Quality Index (PSQI) [16], and Children's sleep status questionnaire [17], included specific questions about children's daytime and nighttime sleep schedules, as well as sleep-related behaviors.

Daytime and nighttime sleep schedules were assessed with seven questions. Four of the questions were as follows. The first and second items were "When does your child normally go to bed on a usual weekday, as well as a weekend day?" Response options were "before 7:00 PM", "between 7:00 and 8:00 PM", "between 8:00 and 9:00 PM", "between 9:00 and 10:00 PM", and "after 10:00 PM". Because of small frequencies, "before 7:00 PM", "between 7:00 and 8:00 PM", "between 8:00 and 9:00 PM" were regrouped into the broader category "before 9:00 PM". The third and fourth items were "When does your child normally wake up on a usual weekday, as well as a weekend day?" Response options were "before 6:00 AM", "between 6:00 and 8:00 AM", "between 8:00 and 9:00 AM", "between 9:00 and 11:00 AM", and "after 11:00 AM". Because of small frequencies, "between 8:00 and 9:00 AM", "between 9:00 and 11:00 AM" and "after 11:00 AM" were regrouped into the broader category "after 8:00 AM". The fifth question was "How long does it take your child fallasleep at night?" Response options were "less than 15 min", "16 $30 \mathrm{~min}$ ", "31 $60 \mathrm{~min}$ " and "more than 60 min". This study categorized falling asleep as "less than $15 \mathrm{~min}$ ", "16 $30 \mathrm{~min}$ " and "more than $30 \mathrm{~min}$ ". The sixth question was an open question: "Indicate how long, in total, your child has slept during the night (on average) in the last month. Do not count the hours that your child is awake". Sleep duration was classified into "less than or equal to the 25th percentile $\left(P_{25}\right)$ of the score $(8.5 \mathrm{~h})$ ", "8.6 9.4 $\mathrm{h}$ " and "greater than or equal to the 75 th percentile $\left(P_{75}\right)$ of the score $(9.5 \mathrm{~h})$ ". The seventh item was "Is your child in the habit of having naps?" Response options were "often", "occasionally" and "no".

Sleep-related problems: night waking, falling sleep in the evening, bed-wetting, bruxism, sweating in sleep, mouth breathing, sleep talking, snoring, nightmares, and shouting in sleep. Each item has five answer options based on the duration of each symptom (none at all, 1 time/week, 2 times/week, $3 \sim 4$ times/week, 5 or more times/week). Total score of sleep-related problems was calculated and then transformed into 3 categories (with less than or equal to $P_{25}$ as no sleep-related problems, $P_{25}$ to $P_{75}$ as occasionally having sleep-related problems, and greater than or equal to $P_{75}$ as often having sleeprelated problems).

\section{ADHD symptoms}

The 10-item Chinese version of the Conners Abbreviated Symptom Questionnaire (C-ASQ) is derived from the Revised Conners Parent Rating Scale [18]. It assesses ADHD symptoms on a 4-point scale ranging from 0 to 3 . It discriminates very well between children with and without ADHD and therefore has been used as a valid screening instrument for the identification and measurement of the behavioral problems of ADHD among children in China [19]. The total score is coded into a categorical variable, with a score $\geq 15$ representing high levels of ADHD symptoms. Its sensitivity, specificity and accuracy are 76.0, 92.9 and $82.1 \%$, respectively [20].

\section{Potential confounding factors}

The factors that were considered potential confounders were socio-demographic characteristics, TV viewing duration on a usual weekday and weekend, and outdoor activities. The socio-demographic characteristic variables included age (from 3 to 6 years old), gender (boy and girl), household registration (urban and rural), parental age (less than or equal to $P_{25}$, between $P_{25}$ and $P_{75}$, and greater than or equal to $P_{75}$ ), and self-reported monthly household income per capita (999 yuan or less, $1000 \sim$ 2999 yuan, and 3000 yuan or more). Education level groups were defined as illiteracy or primary school, junior high school, senior high school, junior college (i.e., $1 \sim 3$ years of college), and university or above (i.e., four or more years of college). Because of small frequencies, illiteracy, primary, and junior high school were regrouped into the broader category "middle school or below". Senior high school and junior college were regrouped into the broader category "senior high school or junior college". Based on this recommendation the American Academy of Pediatrics, TV viewing time was classified into $<1 \mathrm{~h} / \mathrm{d}$ and $\geq 1 \mathrm{~h} / \mathrm{d}$ on weekdays, and $<2 \mathrm{~h} /$ $\mathrm{d}$ and $\geq 2 \mathrm{~h} / \mathrm{d}$ on weekends. Frequencies of outdoor activities were reported as often, sometimes and seldom.

\section{Missing values}

Individuals were excluded from the analyses if she/he had more than $15 \%$ items with missing values. Otherwise, the missing value was replaced by the mean value of that particular item for that individual. 


\section{Data analysis}

Data were entered into an EpiData 3.1 database. All the data were analyzed using the Statistical Package for Social Sciences (SPSS version 13.0). Descriptive analyses were performed on all variables and the prevalence of high levels of ADHD symptoms. Pearson's chi-square was employed to compare the proportions of the independent variables versus the dependent variables. Associations between sleep problems and ADHD symptoms were examined using logistic regression models. Odds ratios (OR) and their 95\% confidence intervals $(C I)$ were calculated. $P$ values less than 0.05 were considered significant for all tests.

\section{Results}

Table 1 represents the general characteristics of preschoolers and the relationship between ADHD symptoms and general characteristics. Approximately 8.6\% (1317) were identified as having high levels of ADHD symptoms, and boys comprised $61.6 \%$ of this group. The rate of high levels of ADHD symptoms decreased with increasing age $\left(X^{2}=32.8, P<0.001\right)$. More boys had high levels of ADHD symptoms than girls $\left(9.9 \%\right.$ vs. $\left.7.2 \%, \chi^{2}=35.59, P<0.001\right)$. Preschoolers with particular factors were more likely to have high levels of ADHD symptoms, such as rural household registration, lower parental age (less than or equal to 28 years), lower parental education level (middle school or below), TV viewing time $\geq 1 \mathrm{~h} / \mathrm{d}$ on weekday and $\geq 2 \mathrm{~h} / \mathrm{d}$ on weekend, and seldom participating in outdoor activities.

Table 2 shows the rates of high levels of ADHD symptoms among preschoolers with different sleep schedules and sleep-related problems. The bedtimes on weekdays and weekends, waking times on weekends, time falling asleep, sleep duration, naps and sleep-related problems were significantly associated with ADHD symptoms in $X^{2}$ tests (all $P<0.05$ ). Preschoolers more likely to have high levels of ADHD symptoms were those who had delayed bedtimes, longer time falling asleep, shorter sleep duration, no naps, and frequent sleep-related problems.

As shown in Table 3, in the logistic regression analysis, after adjusting for TV viewing duration, outdoor activities, and socio-demographic characteristics, delayed bedtime was significantly associated with a risk of high levels of ADHD symptoms, with ORs of 2.50 (95\% CI: $2.09 \sim 3.00)$ and 2.04 (95\% CI: $1.72 \sim 2.42)$ for weekdays and weekends, respectively. Longer time falling asleep ( $\geq 31 \mathrm{~min})(O R=1.76,95 \% C I: 1.47 \sim 2.11)$, no naps $(O R=1.57,95 \% C I: 1.34 \sim 1.84)$ and frequent sleep-related problems $(O R=4.57,95 \%$ CI: $3.86 \sim 5.41)$ were also significantly associated with an increased risk of high levels of ADHD symptoms, while a longer sleep duration $(>8.5 \mathrm{~h})$ was associated with a decreased risk of high levels of ADHD symptoms $(O R=0.76,95 \%$ CI: $0.67 \sim 0.87)$.

\section{Discussion}

The information provided here may help us to understand the prevalence of high levels of ADHD symptoms and the relationships between ADHD symptoms and sleep schedules, sleep-related problems among Chinese preschoolers. This study showed that $8.6 \%$ of the total sample of preschoolers had high levels of ADHD symptoms, including $10.1 \%$ for 3-year-olds, 9.6\% for 4-yearolds, $7.5 \%$ for 5 -year-olds and $7.0 \%$ for 6 -year-olds, with a higher rate in boys (9.9\%) than girls $(7.2 \%)$. The prevalence of ADHD-related behavior, or ADHD symptoms, has been estimated by epidemiological studies to range widely, from 2 to $18 \%$ in Western countries, and the prevalence of ADHD appears to be increasing in these areas [21]. The rate of ADHD symptoms in this study is lower than that reported in the study by Hebrani, et al., which revealed that the prevalence of ADHD in preschool-aged children in northeast Iran was $12.3 \%$ (95\% CI: $10.3 \sim 14.2 \%$ ) [22]. However, the prevalence varies due to a number of factors, including various diagnostic criteria, the age and gender of the population, socioeconomic status, and residence. In Arab countries, the prevalence of total ADHD symptoms, hyperactivetype symptoms and inattention-type symptoms ranged between $1.3 \sim 16 \%, 1.4 \sim 7.8 \%$, and $2.1 \sim 2.7 \%$, respectively [23]. In Iran, among 1403 children aged $3 \sim 6$ years, $362(25.8 \%)$ and 239 (17\%) were classified as having ADHD symptoms according to parents' and teachers' reports, respectively [24]. In Japan, one study indicated that $91(15.6 \%)$ of the 583 children selected were considered to possibly have ADHD [25]. A US-based study reported a significant increase in the parent-reported prevalence of ADHD among $3 \sim 10$-year-old children during 1997-2008 [26]. Previous studies have identified gender, parental education and television watching as risk factors for ADHD symptoms [24, 27], which were findings similar to our results. The prevalence of high levels of ADHD symptoms among preschoolers and its potential long-term consequences make it an important topic to study in relation to risk and protective factors; in addition, these findings strongly imply the need to identify strategies to reduce this problem.

In our nonclinical sample, we found a clear relationship between undesirable sleep schedules (such as delayed bedtimes, longer time falling asleep, shorter sleep duration and no naps), sleep-related problems and ADHD symptoms among preschoolers from a large citywide database in China, which is consistent with findings from previous studies in clinical samples of children with ADHD [28, 29]. A large population study in 10,596 Australian preschool children found that compared to children with mild sleep problems, children with moderate/severe sleep problems (difficulties in initiating and maintaining sleep, snoring and tiredness in the 
Table 1 Sample characteristics of high ADHD symptoms among preschoolers

\begin{tabular}{|c|c|c|c|c|}
\hline Variables & Total & $\begin{array}{l}\text { High ADHD } \\
\text { symptoms [n (\%)] }\end{array}$ & $x^{2}$ & $P$ \\
\hline \multicolumn{5}{|l|}{ Age } \\
\hline 3 year & 3396 & $344(10.1)$ & 32.80 & $<0.001$ \\
\hline 4 year & 4525 & $436(9.6)$ & & \\
\hline 5 year & 4442 & $331(7.5)$ & & \\
\hline 6 year & 2928 & $206(7.0)$ & & \\
\hline \multicolumn{5}{|l|}{ Gender } \\
\hline Male & 8218 & $811(9.9)$ & 35.59 & $<0.001$ \\
\hline Female & 7073 & $506(7.2)$ & & \\
\hline \multicolumn{5}{|l|}{ Only child } \\
\hline Yes & 11,402 & $1005(8.8)$ & 2.31 & 0.129 \\
\hline No & 3889 & $312(8.0)$ & & \\
\hline \multicolumn{5}{|l|}{ Household registration } \\
\hline Rural & 5857 & $582(9.9)$ & 21.14 & $<0.001$ \\
\hline Urban & 9434 & $735(7.8)$ & & \\
\hline \multicolumn{5}{|l|}{ Maternal age } \\
\hline$\leq P_{25}$ (28 year) & 3867 & 459 (11.9) & 71.12 & $<0.001$ \\
\hline$P_{25} \sim P_{75}(29 \sim 34$ year $)$ & 7083 & $549(7.8)$ & & \\
\hline$\geq P_{75}(34$ year $)$ & 4341 & $309(7.1)$ & & \\
\hline \multicolumn{5}{|l|}{ Maternal education } \\
\hline Middle school or below & 6485 & $684(10.5)$ & 73.76 & $<0.001$ \\
\hline $\begin{array}{l}\text { Senior high school or } \\
\text { junior college }\end{array}$ & 6480 & $518(8.0)$ & & \\
\hline University or above & 2326 & $115(4.9)$ & & \\
\hline \multicolumn{5}{|l|}{ Paternal age } \\
\hline$\leq P_{25}$ (31 year) & 4592 & $506(11.0)$ & 48.38 & $<0.001$ \\
\hline$P_{25} \sim P_{75}(31 \sim 37$ year $)$ & 6616 & $497(7.5)$ & & \\
\hline$\geq P_{75}(37$ year $)$ & 4083 & $314(7.7)$ & & \\
\hline \multicolumn{5}{|l|}{ Paternal education } \\
\hline Middle school or below & 5253 & $538(10.2)$ & 44.33 & $<0.001$ \\
\hline $\begin{array}{l}\text { Senior high school or } \\
\text { junior college }\end{array}$ & 7207 & $612(8.5)$ & & \\
\hline University or above & 2831 & $167(5.9)$ & & \\
\hline \multicolumn{5}{|c|}{ Monthly household income per capita(yuan/RMB) } \\
\hline 999 or less & 744 & $61(8.2)$ & 0.71 & 0.701 \\
\hline $1000 \sim 2999$ & 7047 & $596(8.5)$ & & \\
\hline 3000 or more & 7500 & $660(8.8)$ & & \\
\hline \multicolumn{5}{|l|}{ TV viewing time on weekday } \\
\hline$<1 \mathrm{~h} / \mathrm{d}$ & 4089 & $262(6.4)$ & 34.49 & $<0.001$ \\
\hline$\geq 1 \mathrm{~h} / \mathrm{d}$ & 11,202 & $1055(9.4)$ & & \\
\hline \multicolumn{5}{|l|}{ TV viewing time on weekend } \\
\hline$<2 \mathrm{~h} / \mathrm{d}$ & 5395 & $352(6.5)$ & 46.19 & $<0.001$ \\
\hline$\geq 2 \mathrm{~h} / \mathrm{d}$ & 9896 & $965(9.8)$ & & \\
\hline
\end{tabular}

Table 1 Sample characteristics of high ADHD symptoms among preschoolers (Continued)

\begin{tabular}{lllll}
\hline Variables & Total & $\begin{array}{l}\text { High ADHD } \\
\text { symptoms [n (\%)] }\end{array}$ & $x^{2}$ & $P$ \\
\hline Outdoor activities & & & & \\
$\quad$ Often & 8210 & $672(8.2)$ & 16.52 & $<0.001$ \\
Sometimes & 5787 & $495(8.6)$ & & \\
$\quad$ Seldom & 1294 & $150(11.6)$ & & \\
\hline
\end{tabular}

mornings) were 12.1 times more likely to have diagnoses of attention-deficit disorder [28]. Another study documented that compared to the control group (community children), children with ICD-10 hyperkinetic disorder showed significantly delayed bedtimes, stronger bedtime resistance, longer sleep latency, shorter sleep duration, more frequent behavior problems and symptoms such as falling asleep in parents' beds, needing something special to initiate sleep, having nightmares, sleep talking, experiencing sleep bruxism, having a fear of darkness, bedwetting, and, most notably, loud snoring [29]. A metaanalysis by Cortese, et al. addressed this question by examining 16 studies of children and adolescents with ADHD who were not medicated. Children with ADHD were more likely to have bedtime resistance, sleep onset difficulties, night awakenings, difficulties with morning awakenings, sleep-disordered breathing, and daytime sleepiness than non-ADHD controls, according to parent reports [14]. Another recent meta-analysis of relevant polysomnographic studies revealed that ADHD symptoms are related to sleep-disordered breathing [30].

Delayed bedtime was significantly associated with high levels of ADHD symptoms after adjusting for TV viewing duration on weekdays and weekends, outdoor activities and socio-demographic factors. This finding also corresponds to analogous investigations of sleep schedules [31-33]. Kobayashi, et al. found that in comparison to an early bedtime, the $O R$ of an irregular or late bedtime at 2 years of age, with the outcome of attention problems at 8 years of age, was 1.62 (95\% CI: $1.12 \sim 2.36$ ) [31]. Other studies have also reported that short sleep duration was associated with ADHD-like symptoms of inattention [32, 33]. Experimental research has consistently demonstrated that napping during the daytime improves cognitive functioning [34], psychomotor performance, memory and even mood [35]. Although these effects are well established, it remains relatively unknown whether routine napping is common in preschoolers who are likely to benefit from improvements in ADHD symptoms. This study showed that having no naps $(O R=1.57,95 \% \mathrm{CI}$ : $1.34 \sim 1.84$ ) was significantly associated with high levels of ADHD symptoms. Similar to the findings of the previous study, a higher frequency of daily napping was associated with less prosocial behavior and a reduced ability to 
Table 2 The prevalence of high ADHD symptoms among preschoolers with different sleep schedules and sleep-related problems

\begin{tabular}{|c|c|c|c|c|}
\hline $\begin{array}{l}\text { Sleep schedules and } \\
\text { sleep-related problems }\end{array}$ & Total & $\begin{array}{l}\text { High ADHD } \\
\text { symptoms [n (\%)] }\end{array}$ & $x^{2}$ & $P$ \\
\hline \multicolumn{5}{|l|}{ Bedtime on weekday } \\
\hline Before 9:00 PM & 5828 & $417(7.2)$ & 90.54 & $<0.001$ \\
\hline $\begin{array}{l}\text { Between 9:00 and } \\
\text { 10:00 PM }\end{array}$ & 8032 & $685(8.5)$ & & \\
\hline After 10:00 PM & 1431 & $215(15.0)$ & & \\
\hline \multicolumn{5}{|l|}{ Bedtime on weekend } \\
\hline Before 9:00 PM & 3673 & $256(7.0)$ & 53.49 & $<0.001$ \\
\hline $\begin{array}{l}\text { Between } 9: 00 \text { and } \\
\text { 10:00 PM }\end{array}$ & 8300 & $675(8.1)$ & & \\
\hline After 10:00 PM & 3318 & $386(11.6)$ & & \\
\hline \multicolumn{5}{|l|}{ Waking time on weekday } \\
\hline Before 6:00 AM & 629 & $61(9.7)$ & 1.66 & 0.437 \\
\hline $\begin{array}{l}\text { Between 6:00 and } \\
\text { 8:00 AM }\end{array}$ & 14,249 & $1216(8.5)$ & & \\
\hline After 8:00 AM & 413 & $40(9.7)$ & & \\
\hline \multicolumn{5}{|c|}{ Waking time on weekend } \\
\hline Before 6:00 AM & 361 & 39 (10.8) & 9.85 & 0.007 \\
\hline $\begin{array}{l}\text { Between } 6: 00 \text { and } \\
\text { 8:00 AM }\end{array}$ & 9640 & $780(8.1)$ & & \\
\hline After 8:00 AM & 5290 & $498(9.4)$ & & \\
\hline \multicolumn{5}{|l|}{ Time falling asleep } \\
\hline$\leq 15 \min$ & 2813 & $187(6.6)$ & 70.31 & $<0.001$ \\
\hline $16 \sim 30 \mathrm{~min}$ & 8561 & $669(7.8)$ & & \\
\hline$\geq 31 \mathrm{~min}$ & 3917 & $461(11.8)$ & & \\
\hline \multicolumn{5}{|l|}{ Sleep duration } \\
\hline$\leq 8.5 \mathrm{~h}$ & 4570 & $467(10.2)$ & 21.36 & $<0.001$ \\
\hline $8.6 \sim 9.4 h$ & 6458 & $512(7.9)$ & & \\
\hline$\geq 9.5 \mathrm{~h}$ & 4263 & $338(7.9)$ & & \\
\hline \multicolumn{5}{|l|}{ Having naps } \\
\hline Often & 9437 & $728(7.7)$ & 33.19 & $<0.001$ \\
\hline Occasionally & 3737 & $347(9.3)$ & & \\
\hline No & 2117 & $242(11.4)$ & & \\
\hline \multicolumn{5}{|c|}{ Having sleep-related problems } \\
\hline Often & 4017 & $639(15.9)$ & 408.79 & $<0.001$ \\
\hline Occasionally & 6508 & $485(7.5)$ & & \\
\hline No & 4766 & $193(4.0)$ & & \\
\hline
\end{tabular}

address challenges, whereas difficulty in settling for naps was also associated with poorer behavior and adjustment in preschool [36]. In addition, outcomes of a systematic review showed that the evidence regarding behavior is less certain. More systematic and well-designed studies are needed [37].

Poor sleep has deleterious effects on the development of brain functions [38]. It has been suggested that an
Table 3 Crude and Adjusted odds ratios for the relationships between sleep and ADHD symptoms among preschoolers

\begin{tabular}{|c|c|c|c|c|}
\hline \multirow{2}{*}{$\begin{array}{l}\text { Sleep schedules and } \\
\text { sleep-related problems }\end{array}$} & \multicolumn{4}{|c|}{ High ADHD symptoms } \\
\hline & $\begin{array}{l}\text { Crude } \\
\text { OR }(95 \% C l)\end{array}$ & $P$ & $\begin{array}{l}\text { Adjusted }^{\mathrm{a}} \\
\text { OR }(95 \% C l)\end{array}$ & $P$ \\
\hline \multicolumn{5}{|l|}{ Bedtime on weekday } \\
\hline Before 9:00 PM & 1.00 & & 1.00 & \\
\hline $\begin{array}{l}\text { Between 9:00 and } \\
\text { 10:00 PM }\end{array}$ & $1.21(1.06 \sim 1.37)$ & 0.003 & $1.36(1.19 \sim 1.54)$ & $<0.001$ \\
\hline After 10:00 PM & $2.29(1.92 \sim 2.74)$ & $<0.001$ & $2.50(2.09 \sim 3.00)$ & $<0.001$ \\
\hline \multicolumn{5}{|l|}{ Bedtime on weekend } \\
\hline Before 9:00 PM & 1.00 & & 1.00 & \\
\hline $\begin{array}{l}\text { Between 9:00 and } \\
\text { 10:00 PM }\end{array}$ & $1.18(1.02 \sim 1.37)$ & 0.029 & $1.36(1.17 \sim 1.58)$ & $<0.001$ \\
\hline After 10:00 PM & $1.76(1.49 \sim 2.07)$ & $<0.001$ & $2.04(1.72 \sim 2.42)$ & $<0.001$ \\
\hline \multicolumn{5}{|l|}{ Time falling asleep } \\
\hline$\leq 15 \min$ & 1.00 & & 1.00 & \\
\hline $16 \sim 30 \mathrm{~min}$ & $1.19(1.01 \sim 1.41)$ & 0.042 & $1.15(0.97 \sim 1.37)$ & 0.097 \\
\hline$\geq 31 \mathrm{~min}$ & $1.87(1.56 \sim 2.24)$ & $<0.001$ & $1.76(1.47 \sim 2.11)$ & $<0.001$ \\
\hline \multicolumn{5}{|l|}{ Sleep duration } \\
\hline$\leq 8.5 \mathrm{~h}$ & 1.00 & & 1.00 & \\
\hline $8.6 \sim 9.4 \mathrm{~h}$ & $0.76(0.66 \sim 0.86)$ & $<0.001$ & $0.76(0.67 \sim 0.87)$ & $<0.001$ \\
\hline$\geq 9.5 \mathrm{~h}$ & $0.76(0.65 \sim 0.88)$ & $<0.001$ & $0.72(0.62 \sim 0.84)$ & $<0.001$ \\
\hline \multicolumn{5}{|l|}{ Having naps } \\
\hline Often & 1.00 & & 1.00 & \\
\hline Occasionally & $1.23(1.07 \sim 1.40)$ & 0.003 & $1.19(1.04 \sim 1.36)$ & 0.013 \\
\hline No & $1.54(1.32 \sim 1.80)$ & $<0.001$ & $1.57(1.34 \sim 1.84)$ & $<0.001$ \\
\hline \multicolumn{5}{|c|}{ Having sleep-related problems } \\
\hline No & 1.00 & & 1.00 & \\
\hline Occasionally & $1.91(1.60 \sim 2.26)$ & $<0.001$ & $1.91(1.60 \sim 2.26)$ & $<0.001$ \\
\hline Often & $4.48(3.79 \sim 5.30)$ & $<0.001$ & $4.57(3.86 \sim 5.41)$ & $<0.001$ \\
\hline
\end{tabular}

irregular lifestyle and late hours for waking and bedtimes can cause disturbances in various aspects of biological rhythms [39]. ADHD is thought to reflect dysfunctions not only in the prefrontal-striatal circuitry but also in large-scale resting-state neural networks [40]. The mechanisms explaining the relationship between sleep and ADHD are complex, and there are several potential etiologies that are not mutually exclusive. As noted by Owens [41] sleep problems may mimic ADHD symptomatology, exacerbate underlying ADHD symptoms, and be associated with or be exacerbated by ADHD, and the psychotropic medications used to treat ADHD may result in sleep problems.

\section{Strengths and limitations}

Some strengths and limitations should be noted. First, this study was cross-sectional, which did not allow for causality 
or the direction of relationships to be determined. However, the appropriate analysis of cross-sectional data represents a useful initial step in identifying associations between sleep schedules, sleep-related problems and ADHD symptoms. Second, the study subjects were sampled within Ma'anshan city. It is appropriate to assume that the sampled population represents the preschoolers in the city of Maanshan, but it is far from being a good sample at the provincial or national level. Third, our study incorporated only the subjective measures obtained from caregiver reports. Further studies are needed that utilize objective sleep measures for assessing the relationship between sleep physiopathology and ADHD symptoms in Chinese preschoolers.

Despite these limitations, this study investigated the prevalence of high levels of ADHD symptoms and examined the associations between sleep schedules, sleeprelated problems and ADHD symptoms based on data from a citywide representative sample of preschoolers in mainland China. The findings suggest that high levels of ADHD symptoms were fairly common among Chinese preschoolers and underpin the importance of understanding the relationship between sleep schedules, sleep-related problems and ADHD symptoms. Future studies may be warranted to investigate whether improvement in sleep schedules and sleep-related problems in preschoolers can alleviate ADHD at a later age. The health department of the Chinese government has now recognized high levels of ADHD symptoms as a serious public health problem. Arguably, it is time for the World Health Organization and health departments around the world to develop effective health policies to increase public awareness of high levels of ADHD symptoms.

\section{Conclusions}

In conclusion, nearly 1 in 10 children aged $3 \sim 6$ years old have high levels of ADHD symptoms in China. Given the significant association between undesirable sleep schedules, sleep-related problems and ADHD symptoms among preschoolers, our results highlight that beneficial and regular sleep habits potentially attenuate ADHD symptoms among preschoolers. It might be meaningful for child health practitioners to include these findings regarding sleep schedules and related problems in their assessments of children with ADHD-related symptoms.

\footnotetext{
Abbreviations

$X^{2}$ : Chi square; ADHD: Attention deficit and hyperactivity disorder; C-ASQ: Conners' abbreviated symptom questionnaire; Cl: Confidence interval; CSHQ: Children's sleep habits questionnaire; OR: Odds ratio
}

\section{Acknowledgments}

The authors are grateful to all the colleagues working in Health Care Department of Maternal and Child Health Centers in Maanshan, Department of Maternal and Child Health of Anhui Medical University for help in data collection, all the teachers who readily helped and consented to carry out the study during kindergarten, as well as to all the participated children' caregivers.

\section{Funding}

The study was carried out with financial support of the second batch of Anhui provincial health office research projects (grant numbers 13FR006) and National Natuural Science Fundation of China (grant number 81573168).

\section{Availability of data and materials}

The datasets generated during and/or analysed during the current study are not publicly available due to property right but are available from the corresponding author on reasonable request.

\section{Authors' contributions}

$\mathrm{HC}$, SQY and FBT conceived of the idea for the manuscript and designed the study. HC performed the statistical analysis, interpreted the data. HC, SQY and FBT drafted the manuscript. HC, SQY, CLG, SMW, LLN, HHT, TS, YQX and FBT conducted the data collection. All authors critically revised the manuscript, and read and approved the submitted manuscript.

\section{Ethics approval and consent to participate}

The project was approved by Biomedicine Ethical Committee in Anhui Medical University. Informed consent obtained from all the participating caregivers of children was written.

\section{Consent for publication}

Not applicable

Competing interests

The authors declare that they have no competing interests.

\section{Publisher's Note}

Springer Nature remains neutral with regard to jurisdictional claims in published maps and institutional affiliations.

\section{Author details}

'Ma'anshan Maternity and Child Health Care Hospital, Ma'anshan, Anhui 243000, China. ${ }^{2}$ Department of Maternal, Child and Adolescent Health, School of Public Health, Anhui Medical University, 81 Mei Shan Road, Hefei, Anhui 230032, China. ${ }^{3}$ Anhui Provincial Key Laboratory of Population Health and Aristogenics, Hefei 230032, China.

Received: 24 November 2016 Accepted: 29 January 2018

Published online: 19 February 2018

\section{References}

1. Cherkasova M, Sulla EM, Dalena KL, Pondé MP, Hechtman L. Developmental course of attention deficit hyperactivity disorder and its predictors. J Can Acad Child Adolesc Psychiatry. 2013;22(1):47-54.

2. Richa S, Rohayem J, Chammai R, Kazour F, Haddad R, et al. ADHD prevalence in Lebanese school-age population. J Atten Disord. 2014;18(3):242-6.

3. Bener A, Qahtani RA, Abdelaal I. The prevalence of ADHD among primary school children in an Arabian society. J Atten Disord. 2006;10(1):77-82.

4. Polanczyk G, de Lima MS, Horta BL, Biederman J, Rohde LA. The worldwide prevalence of ADHD: a systematic review and metaregression analysis. Am J Psychiatry. 2007;164(6):942-8.

5. Gau SS, Chong MY, Chen TH, Cheng AT. A 3-year panel study of mental disorders among adolescents in Taiwan. Am J Psychiatry. 2005;162(7):1344-50.

6. Posner K, Melvin GA, Murray DW, Gugga SS, Fisher P, Skrobala A, et al. Clinical presentation of attention-deficit/hyperactivity disorder in preschool children: the preschoolers withAttention-deficit/hyperactivity disorder treatment study (PATS). J Child Adolesc Psychopharmacol. 2007;17(5):547-62.

7. Lahey BB, Pelham WE, Loney J, Kipp H, Ehrhardt A, Lee SS, et al. Three-year predictive validity of DSM-IV attention deficit hyperactivity disorder in children diagnosed at 4-6 years of age. Am J Psychiatry. 2004;161(11):2014-20.

8. Willcutt EG. The prevalence of DSM-IV attention-deficit/hyperactivity disorder: a meta-analytic review. Neurotherapeutics. 2012;9(3):490-9.

9. Biederman J, Faraone SV. Attention-deficit hyperactivity disorder. Lancet. 2005:366(9481):237-48

10. Sivertsen B, Harvey AG, Reichborn-Kjennerud T, Torgersen L, Ystrom E, Hysing M. Later emotional and behavioral problems associated with sleep problems in toddlers: a longitudinal study. JAMA Pediatr. 2015;169(6):575-82. 
11. Nelson TD, Nelson JM, Kidwell KM, James TD, Espy KA. Preschool sleep problems and differential associations with specific aspects of executive control in early elementary school. Dev Neuropsychol. 2015;40(3):167-80.

12. Scott N, Blair PS, Emond AM, Fleming PJ, Humphreys JS, Henderson J, et al. Sleep patterns in children with ADHD: a population-based cohort study from birth to 11 years. J Sleep Res. 2013;22(2):121-8.

13. Abou-Khadra MK, Amin OR, Shaker OG, Rabah TM. Parent-reported sleep problems, symptom ratings, and serum ferritin levels in children with attention-deficit/hyperactivity disorder: a case control study. BMC Pediatr. 2013;13:217-23.

14. Cortese S, Faraone SV, Konofal E, Lecendreux M. Sleep in children with attention-deficit/hyperactivity disorder: meta-analysis of subjective and objective studies. J Am Acad Child Adolesc Psychiatry. 2009;48(9):894-908.

15. Owens JA, Spirito A, McGuinn M. The Children's sleep habits questionnaire (CSHQ): psychometric properties of a survey instrument for school-aged children. Sleep. 2000;23(8):1043-51.

16. Buysse DJ, Reynolds CF 3rd, Monk TH, Berman SR, Kupfer DJ. The Pittsburgh sleep quality index: a new instrument for psychiatric practice and research. Psychiatry Res. 1989;28(2):193-213.

17. Liu YP, Huang GW, Ma M, Hu JY. Epidemiological survey on sleep problems in children of 2-6 years and analysis of its influencing factors. Chinese Journal of Clinical Rehabilitation. 2006;10(30):69-71.

18. Goyette $\mathrm{CH}$, Conners CK, Ulriech RF. Normative data on revised Conners parent and teacher rating scale. J Abnorm Child Psychol. 1978;6(2):221-36.

19. Huang $Y$, Zheng $S, X u C$, Lin K, Wu K, Zheng M, et al. Attention-deficit hyperactivtiy disorder in elementary school students in Shantou, China: prevalence, subtypes, and influencing factors. Neuropsychiatr Dis Treat. 2017;13:785-92.

20. O P, Chen X, Qian QF. The value of Conners' abbreviated symptom questionnaire in the diagnosis of attention deficit/hyperactivity disorder. Chinese Journal of Child Health Care. 2001;9(3):201.

21. Rowland AS, Lesesne CA, Abramowitz AJ. The epidemiology of attentiondeficit/hyperactivity disorder (ADHD): a public health view. Ment Retard Dev Disabil Res Rev. 2002;8(3):162-70.

22. Hebrani P, Abdolahian E, Behdani F, Vosoogh I, Javanbakht A. The prevalence of attention deficit hyperactivity disorder in preschool-age children in Mashhad, north-east of Iran. Arch Iran Med. 2007;10(2):147-51.

23. Alhraiwil NJ, Alhraiwil NJ, Ali A, Househ MS, Al-Shehri AM, Systematic EMAA. Review of the epidemiology of attention deficit hyperactivity disorder in Arab countries. Neurosciences (Riyadh). 2015;20(2):137-44.

24. Meysamie A, Fard MD, Mohammadi MR. Prevalence of attention-deficit/ hyperactivity disorder symptoms in preschool-aged Iranian children. Iran J Pediatr. 2011;21(4):467-72.

25. Nomura K, Okada K, Noujima Y, Kojima S, Mori Y, Amano M, et al. A clinical study of attention-deficit/hyperactivity disorder in preschool children-prevalence and differential diagnoses. Brain and Development. 2014;36(9):778-85.

26. Boyle CA, Boulet S, Schieve LA, Cohen RA, Blumberg SJ. Yeargin-Allsopp, et al. trends in the prevalence of developmental disabilities in US children, 1997-2008. Pediatrics. 2011;127(6):1034-42.

27. Yousef S, Eapen V, Zoubeidi T, Mabrouk A. Behavioral correlation with television watching and videogame playing among children in the United Arab Emirates. Int J Psychiatry Clin Pract. 2014;18(3):203-7.

28. Hiscock H, Canterford L, Ukoumunne OC, Wake M. Adverse associations of sleep problems in Australian preschoolers: national population study. Pediatrics. 2007:119(1):86-93.

29. Gomes AA, Parchão C, Almeida A, Clemente V, Pinto de Azevedo MH. Sleep-wake patterns reported by parents in hyperactive children diagnosed according to ICD-10, as compared to paired controls. Child Psychiatry Hum Dev. 2014;45(5):533-43.

30. Sedky K, Bennett DS, Carvalho KS. Attention deficit hyperactivity disorder and sleep disordered breathing in pediatric populations: a meta-analysis. Sleep Med Rev. 2014;18(4):349-56.

31. Kobayashi K, Yorifuji T, Yamakawa M, Oka M, Inoue S, Yoshinaga H, et al. Poor toddler-age sleep schedules predict school-age behavioral disorders in a longitudinal survey. Brain and Development. 2015;37(6):572-8.

32. Lehto JE, Uusitalo-Malmivaara L. Sleep-related factors: associations with poor attention and depressive symptoms. Child Care Health Dev. 2014;40(3):419-25.

33. Gruber R, Michaelsen S, Bergmame L, Frenette S, Bruni O, Fontil $L$, et al. Short sleep duration is associated with teacher-reported inattention and cognitive problems in healthy school-aged children. Nat Sci Sleep. 2012:4: $33-40$.
34. Lovato $N$, Lack $L$. The effects of napping on cognitive functioning. Prog Brain Res. 2010;185:155-66.

35. Tucker MA, Fishbein W. Enhancement of declarative memory performance following a daytime nap is contingent on strength of initial task acquisition. Sleep. 2008;31(2):197-203.

36. Hall WA, Scher A, Zaidman-Zait A, Espezel H, Warnock FA. Communitybased study of sleep and behaviour problems in 12- to 36-month-old children. Child Care Health Dev. 2012;38(3):379-89.

37. Thorpe K, Staton S, Sawyer E, Pattinson C, Haden C, Smith S. Napping development and health from 0 to 5 years: a systematic review. Arch Dis Child. 2015:100(7):615-22.

38. Turnbull K, Reid GJ, Morton JB. Behavioral sleep problems and their potential impact on developing executive function in children. Sleep. 2013; 36(7):1077-84

39. Kohyama J. A newly proposed disease condition produced by light exposure during night: asynchronization. Brain and Development. 2009; 31(4):255-73.

40. Castellanos FX, Proal E. Large-scale brain systems in ADHD: beyond the prefrontal-striatal model. Trends Cogn Sci. 2012;16(1):17-26.

41. Owens JA. The ADHD and sleep conundrum: a review. J Dev Behav Pediatr. 2005;26(4):312-22

\section{Submit your next manuscript to BioMed Central and we will help you at every step:}

- We accept pre-submission inquiries

- Our selector tool helps you to find the most relevant journal

- We provide round the clock customer support

- Convenient online submission

- Thorough peer review

- Inclusion in PubMed and all major indexing services

- Maximum visibility for your research

Submit your manuscript at www.biomedcentral.com/submit
) Biomed Central 